\title{
A "Rocambolesque" Strategy To Combat Definitively Lichen Simplex Chronicus In Black Skinned People.
}

\author{
Texia Research ${ }^{1}$, Lorenzo Martini ${ }^{2}$ \\ ${ }^{1}$ Texia Research-Eu-TURIN, ${ }^{2}$ Department of Pharmaceutical Biotechnologies University of Siena
}

\begin{abstract}
Scope of our study is to treat Lichen simplex chronicus that is very evident in white people so that all Researchers of the Occidental World focus their attention to this concern, forgetting to observe that the same Lichen simplex in dark skinned people is less evident, but more fastidious and is a real disease that must be treated using different remedies than those employed for Caucasians. We have alternated two natural cosmetics produced in Italy, the former acting as mild keratolytic and antibacterial, the latter as alleviative and demulcent, so that at the end of the experimentations all black spots disappear and no pinkish blur remains onto dark skin.
\end{abstract}

Keywords: LSC, black skinned people, menthyl lactate, capsicum annuum fruit extract.

\section{Background}

Lichen simplex chronicus (LSC) is not but the thickening of the skin with variable scaling that arises secondary to repetitive scratching or rubbing. Lichen simplex chronicus is not a primary process. Rather, a person senses pruritus in a specific area of skin (with or without underlying pathology) and causes mechanical trauma to the point of lichenification. A proposed variant of lichen simplex chronicus is lichen amyloidosis. Lichen amyloidosis is described as lichen simplex chronicus in which the keratinocytes have necrosed and formed keratinocytic-derived amyloid in the dermis. The initial insult is pruritus with resultant amyloid formation, rather than the reverse. (1) Lichen simplex chronicus is found on the skin in regions accessible to scratching. Pruritus provokes rubbing that produces clinical lesions, but the underlying pathophysiology is unknown. Some skin types are more prone to lichenification, such as skin that tends toward eczematous conditions (ie, atopic dermatitis, atopic diathesis). A relationship likely exists between central and peripheral neural tissue and inflammatory cell products in the perception of itch and ensuing changes in lichen simplex chronicus.Sometimes LSC is defined a neurodermatiti tout court. Emotional tensions, such as in patients with anxiety, depression, or obsessive-compulsive disorder, may play a key role in inducing a pruritic sensation, leading to scratching that can become self-perpetuating. The possible interplay among primary lesions, psychic factors, and the intensity of pruritus additively influence the extent and severity of lichen simplex chronicus..

Notwithstanding manifold AA refer that no differences are reported in frequency among races, although prior authors claimed lichen simplex chronicus was more common in Asians and African Americans. The appearance of lesions on darker skin sometimes shows follicular prominence. Secondary pigmentary alterations are also more severe in individuals with darker skin. Lichen simplex chronicus is observed more commonly in females than in males. Lichen nuchae is a form of lichen simplex that occurs on the midposterior neck and is observed almost exclusively in women.

Lichen simplex chronicus occurs mostly in mid-to-late adulthood, with highest prevalence in persons aged 30-50 years. Generally Treatment is aimed at reducing itching and minimizing existing lesions because rubbing and scratching exacerbate LSC. The itching and inflammation may be treated with a lotions or steroid cream (such as Betamethasone) applied to the affected area of the skin.Nighttime scratching can be reduced with sedatives and antihistamines. When Lichen simplex chronicus affests Latin Americans (especially mexicans or people form Costa Rica or Panama) and Asian dark-skinned females, attempts to treat this syndrom is very difficult, as at the basis of the problem there is the complication of different melanization between Caucasian and Asian or Black phenotypes.

Generally reiterated applications of excimer-laser are suggested, even if relapses are too often common (it is probably due to the different action of tyrosinase, responsible of transformation from monoquinones to polyquinones,idest eumelanins in black skinned people respect to Caucasians). Many AA suggest the usage of Copper blockers to antagonize the enzyme in black people, but Copper blockers are rightly considered perilous (they are commonly used to destroy little birds, rodents, and fastidiuous insects), or massive use of topical applications of ascorbic acid (many indigenous populations of Horn of Africa use to spread the juice of tropical fruits extremely rich in vit. C, as Baobab fruits). In 50s of last century manifold were the patents disclaiming the usage of salts of mercury or mercaptans, extremely dangerous for Man's Health and now all these products are banished at all. 
Besides the component of the black spost, that is cosmetically inacceptable, there is always the problem of nocturnal itch, that compromises a good standard of life of the people who are affected by this disease. Even dermoabrasion is suggested by manifold aesthetical surgeons, but even this practice requires reiterated applications, since lichen reappears periodically, especially at seasonal changes.

Hydroquinone at high dosages (more than $2 \%$ ) is now banished and it must be considered that on dark skin, the black spots treated by hydroquinone will appear as vitiligo, and so, cosmetically speaking, it will represent a cruel jink for black skinned people. Eczemas and atopic dermatities in black skinned people are often evoked by Gram + bacteria and it is recognized that silver citrate acts strongly against Gram+, Gram(especially the skin bacterial flora) and even against yeasts and moulds.(4) Just in case of mycotic coinfestation, observable in the cases of eczemas and atopic dermatities in dark skinned people, chloroxylenol (it is admitted only in percentage of $0.5 \%$ ), is more than sufficient to perform its spectacular action against fungi and dermatophytes. $(4,5,6,7,8,9)$. In order to avoid the fastidious nocturnal itching, we have decided to insert in the complete treatment the complex menthyl-lactate and capsicum annuum fruit extract, that is recognised to alleviate the sensation of severe pruritus, as it is apt to alternate the feeling of cold and hot on skin nociceptors.

\section{Materials and methods.}

The two volunteers we have invited to try our emulsions are:

A) Woman $49 \mathrm{y}$. old from Costa Rica (her black spots indicating the presence of lichen simplex chronicus dislocated onto neck and face, especially on cheekbones.

B) Her son, 22 y. old, male, who presents L.S.C. even on chest and groin.

We have prepared two emulsions to spread alternatively every 4 hours (idest 4 times during the 16 hours a normal person is awake and active) for 5 days consecutively.

Cream A had to be spread at 8.00 a.m. in the morning, cream B at 12 o'clock, cream A again at 4.00 p.m and cream B finally at 8.00 p.m.

We have behold optimal results after only 5 days.

The first cream (that is " $\mathrm{A}$ ", to be applied on the morning and in the afternoon) contained:

Chlorhexidine Digluconate,

Tridecyl Salicylate,

Sodium Salicylate,

Panthenol

Niacinamide

Silver citrate and chloroxylenol.

This first emulsion is useful to struggle bacterial and mycotic assaults and acts as a bland and keratolytic synergic complex, soft and delicate, that does not involve redness and irritation in the zones affected from lichen simplex.

The second emulsion ( the "B") contained:

Urea,

carthamus tinctorius seed oil,

allantoin,

capsicum annuum fruit extract,

tocopherol,

biasbolol,

menthyl lactate

ceramides

and the main scope of the latter cream is to alleviate the feeling of intense itch and let the skin become smooth and soft, as it acts as demulcent.

We have treated a zone of 3 square inches in the neck of the woman and another zone of 3 square inches in the inner thigh of her son.

The woman's zone presented 9 black spots, rugged and craggy.

The boy'ss zone presented 7 black spots, a bit more extensive than these of his mother.

\section{Results}

In the following table is possible to notice the progressive disappearance of the spots (by number) day after day, both in the case of the mother (1) and in the case of the son (2). 
Table I: number of spots disappearing during the treatment with the two creams in 5 days.

\begin{tabular}{|l|l|l|l|l|l|l|}
\hline Case & $\begin{array}{l}\text { Number of } \\
\text { spots at very } \\
\text { first day }\end{array}$ & $\begin{array}{l}\text { Number of } \\
\text { spots at 2nd } \\
\text { day }\end{array}$ & $\begin{array}{l}\text { Number of } \\
\text { spots at 3rd } \\
\text { day }\end{array}$ & $\begin{array}{l}\text { Number of } \\
\text { spots at ath } \\
\text { day }\end{array}$ & $\begin{array}{l}\text { Number of } \\
\text { spots at 5th } \\
\text { day }\end{array}$ \\
\hline 1 & 9 & 6 & 4 & 2 & 0 \\
\hline 2 & 7 & 4 & 2 & 1 & 0 \\
\hline
\end{tabular}

\section{Discussions and Conclusions}

It is important to reflect that lichen simplex cannot be treated by a simplest and strong abrasion or using drastic exfoliating agents, with no aids of emollients and hydration enhancers. The alternance of a "medical" campaign that wants to eradicate the bacterial flora, cause of the lichen, acting simultaneously as mild keratolytic and another strategy intending to struggle the itch and discomfort, has resulted a very special surprise. It is very interesting the fact that the proofs have been made on black skinned people, where it is supposed that black spots can be confused with the same dark colour of the skin itself.

\section{Aknowledgnments}

The corresponding Author is proud of the fact that the study has been realised thanks to two products of his firm.Products are called Exfo 20 and Lenimax.

\section{References}

[1] Lotti T; Buggiani G, Prignano F; Prurigo nodularis and lichen simplex chronicus.2008; Dermatologic Therapy. 21 (1): $42-46$

[2] 2)Lynch P J.. Lichen simplex chronicus (atopic/neurodermatitis) of the anogenital region.. Dermatologic Therapy.2004. 17 (1): 819.

[3] SCCP/1196/08 O, Opinion on citric acid (and) silver citrate, 19th plenary of 21 January 2009

[4] WHO Model Formulary 2008 (PDF). World Health Organization. 2009. p. 324

[5] Griffiths C, Barker J, Bleiker T, Chalmers R, Creamer D: Rook’s Text of Dermatology, 9th Ed.2017.John Wiley \& Sons. 128.38

[6] Digison, MB;A review of anti-septic agents for pre-operative skin preparation.". Plastic surgical nursing : official journal of the American Society of Plastic and Reconstructive Surgical Nurses. 2007; 27 (4): 185-9

[7] Mahon C R.; Donald L, Manuselis G,(2014). Textbook of Diagnostic Microbiology (5 ed.). Elsevier Health Sciences. 2014: p. 67

[8] Larson, E; Talbot, GH; An approach for selection of health care personnel handwashing agents.". Infection control .1986: 7 (8): 419-24.

[9] "Chloroxylenol". International Drug Price Indicator Guide. Retrieved 8 December 2016. 